\title{
Development of the testbench base on STM32 microcontroller and expansion module
}

\author{
Tatiana Litvinenko \\ Department of Design and Operation of \\ Electronic Devices \\ Kharkiv National University \\ of Radio Electronics \\ Kharkiv, Ukraine \\ tetiana.lytvynenko@nure.ua
}

\author{
Mikhail Kuznetsov \\ Department of Design and Operation of \\ Electronic Devices \\ Kharkiv National University \\ of Radio Electronics \\ Kharkiv, Ukraine \\ mykhailo.kuznetsov1@nure.ua
}

\author{
Pavlo Galkin \\ ORCID 0000-0002-0558-6448 \\ Department of Design and Operation of \\ Electronic Devices \\ Kharkiv National University \\ of Radio Electronics \\ Kharkiv, Ukraine \\ pavlo.halkin@nure.ua
}

\begin{abstract}
The purpose of the development is to create a test layout on the STM32 microcontroller F103C8 series and expansion module. Performing this work had to consider the following steps: analysis of similar devices and expansion modules; develop the spatial structure of the device and its layout; develop the design of the printing module; conduct testing; integrate the test layout and expansion module.
\end{abstract}

Keywords-STM32, microcontroller, expansion module, testbench, F103C8, SPI, I2C, GPIO, testing

\section{INTRODUCTION}

A test bench or testing workbench is an environment used to verify the correctness or soundness of a design or model [1]. The Wireless sensor networks (WSN) systems have a lot of problems like security, energy consumption, heterogeneity and other disadvantages that need be solved. Therefore, it is quite difficult to design a sensor network node so that it satisfies the necessary criteria for optimality. If such a node is also used for testing and training, then additional requirements for the construction will be propose to, for example, as in articles of designing microprocessor systems [2] or embedded control systems [3]. Energy monitoring [4] is a key factor for the successful prolongation of life times each nodes in wireless sensor network, for examples reducing the power consumption of nodes [5]. Therefore, can set the task to optimize the structure of the node for as one of approach to designing a wireless sensor network node. One approach is shown in the literature [6].

STM32 is a family of 32-bit microcontrollers from STMicroelectronics. STM32 chips are grouped in series, each using the same 32-bit ARM core.

Performing this work had to consider the following steps: analysis of similar devices and expansion modules; develop the spatial structure of the device and its layout; develop the design of the printing module; conduct testing; integrate the test layout and expansion module.

\section{ANALYSIS OF SimilaR DEVICES AND EXPANSION MODULES}

We analyzed various approaches to the design of such stands - with the presence of a scheme for additional installation (fig.1) and without it (fig. 2).

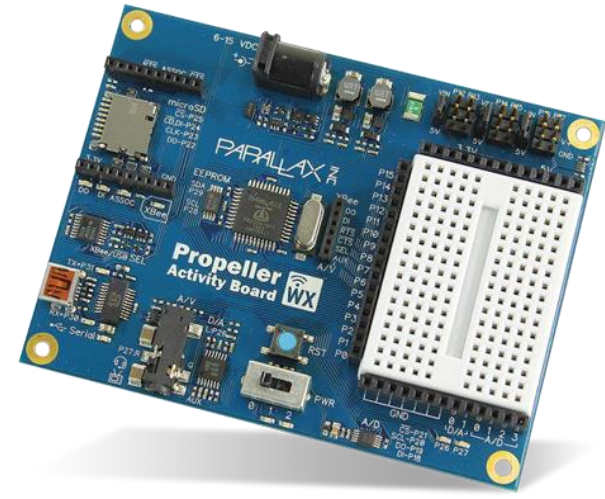

Fig.1 PCB testbench board with additional installation

The stand (fig. 2) is built on a modern element base. The stand includes two standard RS-232C ports, serial Flash memory with $\mathrm{I} 2 \mathrm{C}$ interface, program memory and $64 \mathrm{~KB}$ data memory. The presence of system and peripheral interfaces allows using the stand for debugging any systems.

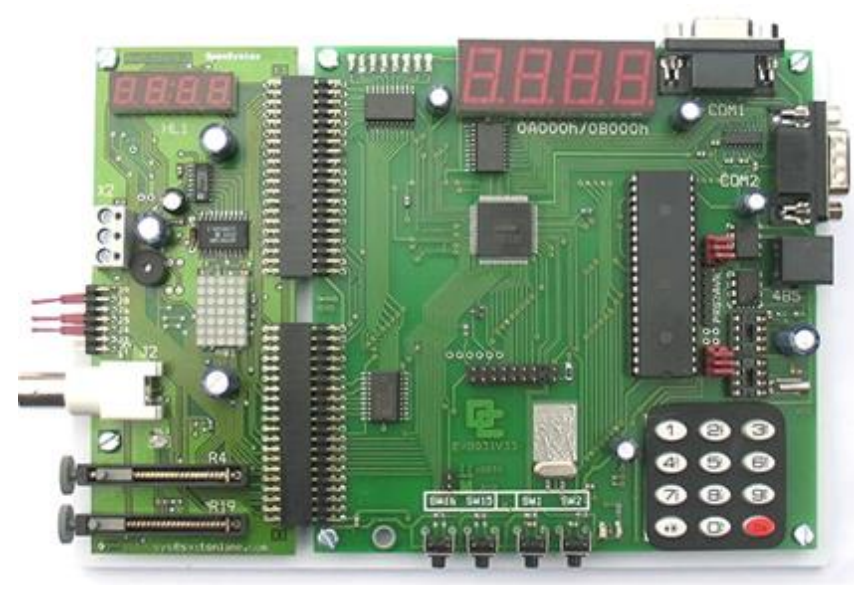

Fig.2 PCB testbench board with expansion module

\section{DeVelopment of the Module Structure}

Were analyzed STM32 microcontroller F103C8 series (fig. 3). 


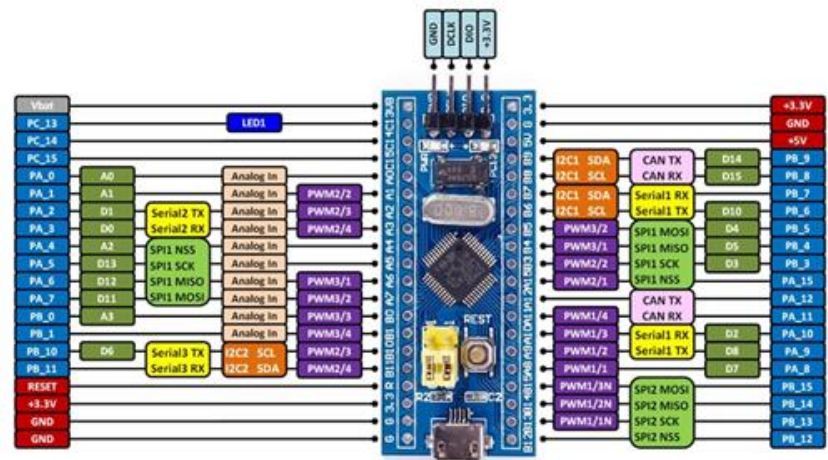

Fig.3 STM32 microcontroller F103C8 series with pireferals

As a result of the analysis and design, a printed circuit board was developed and the module was assembled. The figure 4 shows the appearance of the text layout and its layout.

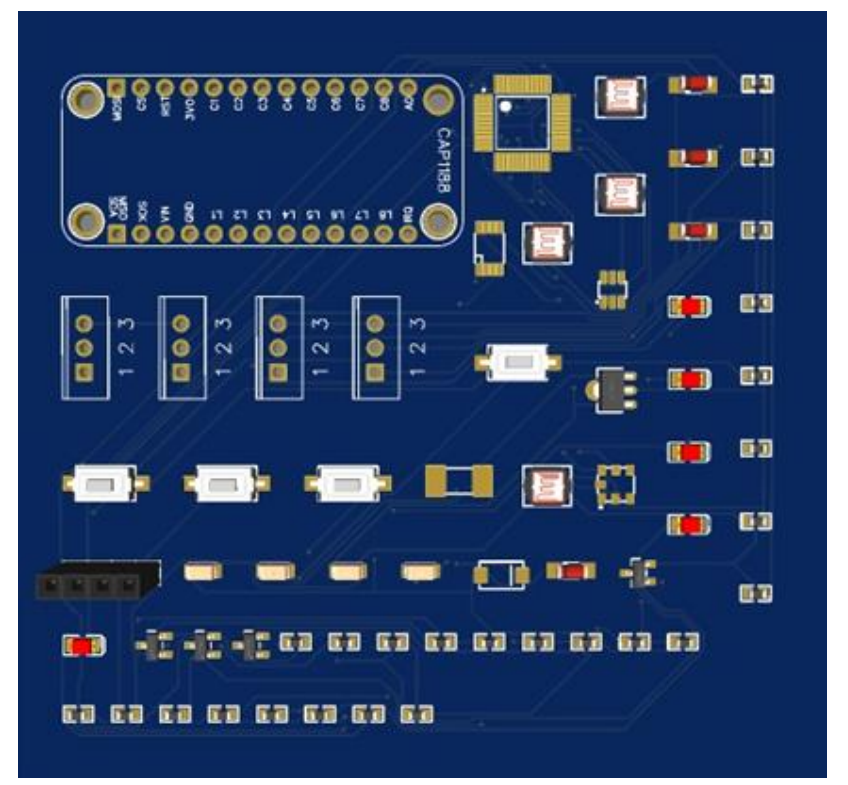

Fig.4 STM32 testbench base on STM32 microcontroller F103C8 series

The developed expansion module is shown in the fig. 5 .

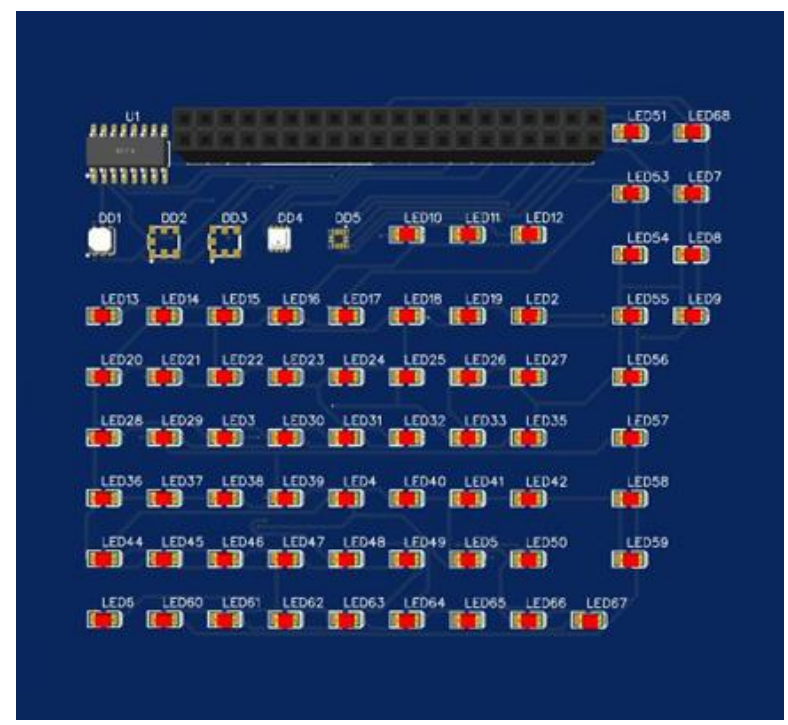

Fig.5 Developed expansion module
The proposed model defining defines different levels of system interaction. Each level performs certain functions in such interaction (fig. 6).
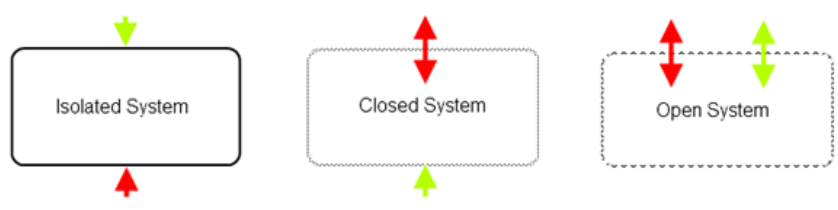

exchange of energy

exchange of matter

I System boundaries

Fig.6 Proposed model for testbench

\section{CONCLUSION}

Similar constructions and modules are analyzed[1,3,6-8]. A test layout based on the STM32 microcontroller has been developed. An extension module for test layouts has been developed. Three different models for testing embedded systems have been proposed.

\section{REFERENCES}

[1] Zhong H. et al. The development of a real-time hardware-in-the-loop test bench for hybrid electric vehicles based on multi-thread technology //2006 IEEE International Conference on Vehicular Electronics and Safety. - IEEE, 2006. - C. 470-475.

[2] C. Alvarado, F. Bosquez, Palacios and L. Córdoba, "Low-energy Adaptive Clustering Hierarchy protocol and optimal number of cluster head algorithm in a randomized wireless sensor network deployment," 2017 International Conference on Electrical, Electronics, Communication, Computer, and Optimization Techniques (ICEECCOT), Mysuru, 2017, pp. 1-4. oi: 10.1109/ICEECCOT.2017.8284632

[3] P. Galkin, "Razrabotka laboratornogo kompleksa po izucheniyu vstraivaemyih sistem upravleniya i promyishlennoy avtomatizatsii [Development of a laboratory complex for the study of embedded control systems and industrial automation]," Materials of the 21st International Youth Forum "Radio Electronics and Youth in the 21st Century", April 25-27, 2017 Conference "Automated systems and computerized technologies of radio-electronic instrument-making", Kharkiv, KNURE, vol. 2, P.94-95. (In Russian).

[4] P.V. Galkin. "Analiz energopotrebleniya uzlov besprovodnih sensornih setei [Analysis of power consumption of nodes of wireless sensor networks], “ ScienceRise, no.2 pp 55-61, 2014. (In Russian).

[5] P. Galkin, "Model of Reducing the Power Consumption for Node of Wireless Sensor Network in Embedded Control Systems," 2018 International Scientific-Practical Conference Problems of Infocommunications. Science and Technology (PIC S\&T), Kharkiv, Ukraine, 2018, pp. 252-256. doi: 10.1109/INFOCOMMST.2018.8631891

[6] Approaches to Designing a Wireless Sensor Network Node for IoT Solution / A. Sukov, A. Zayanchukovsky, V. Olizarenko, P. Galkin // II International Scientific and Practical Conference Theoretical and Applied Aspects of Device Development on Microcontrollers and FPGAs (MC\&FPGA), Kharkiv, Ukraine, 2020, pp.10-11.

[7] P. Galkin, "Design Testbench for Wireless Sensor Network Based on CC2530 Transceiver," 2019 IEEE International Scientific-Practical Conference Problems of Infocommunications, Science and Technology (PIC S\&T), 2019, pp. 1-6, doi: 10.1109/PICST47496.2019.9061352.

[8] P. Galkin, R. Umiarov and O. Grigorieva, "Design Embedded System Testbench Based on FPGA and Microcontrollers for TATU Smart $\mathrm{Lab}$ as Education Component of Industry 4.0," 2019 IEEE 2nd Ukraine Conference on Electrical and Computer Engineering (UKRCON), 2019, pp. 628-633, doi: 10.1109/UKRCON.2019.8879996. 